\title{
The Cognitive of Collective Action in Campaign-Based Watershed Management: The Case of Farmers in Ethiopian Highlands
}

\author{
Alemayehu Temesgen Gebremikael \\ School of Rural Development and Agricultural Innovation, Haramaya University, Oromia, Ethiopia \\ Email address: \\ temesgenalemayoo@gmail.com
}

\section{To cite this article:}

Alemayehu Temesgen Gebremikael. The Cognitive of Collective Action in Campaign-Based Watershed Management: The Case of Farmers in Ethiopian Highlands. International Journal of Natural Resource Ecology and Management. Vol. 6, No. 3, 2021, pp. 93-107.

doi: 10.11648/j.ijnrem.20210603.11

Received: May 31, 2021; Accepted: July 12, 2021; Published: July 21, 2021

\begin{abstract}
With the increased importance of collective action in many phases of natural resource management, it is necessary to focus on farmers' cognitive abilities, such as intellect, social capital (social relationships), and orientation (symmetric information), which enhance group or team ability to solve problems through collective action, not missing physical abilities. Due to low land efficiency as a result of land degradation, the regime is reliant on continuing watershed management collective activity. Participating in a large-scale collective activity could be facilitated by different populations' cognitive abilities. As a result, this review article examined cognitive collective action in campaign-based watershed management in Ethiopia's highlands, as well as how cognition is linked to physical practices and what factors influence farmers' decisions to participate in collective action. Then, through strategic and expanded kinds of cooperative games, experimental games were taken. This has been done using both conceptual and analytical frameworks. Web Science Page Googled and reviewed a total of eighty-one articles and published books. Then, at the end, their connections and gaps in the literature were highlighted. As a result, it is plausible to conclude that investing in farmers' collective action cognition can result in beneficial changes in land degradation. As a result, future academics and policymakers should concentrate on: 1) integrating social capital and collective orientation with watershed management to support collective action. 2) The interplay between cognitive (mental) and physical abilities. 3) Amending property rights and strengthening institutions. As a result, researchers can use the findings to develop policy and extension efforts that prioritize future farmer cognition.
\end{abstract}

Keywords: Cognitive, Collective Action, Campaign-Based, Watershed Management

\section{Introduction}

\subsection{Background of the Review}

The Ethiopian highlands housed about $85 \%$ of the population and held $95 \%$ of the total cropland $[35,44]$. The visible type of land degradation affecting farms was moderate to severe soil erosion, which affected around $80 \%$ of its area [78].

One of the most complex environmental problems in Ethiopia's highlands was degradation caused by soil erosion and later nutrient loss [61]. Over cultivation, excessive population pressure, and deforestation all contributed to soil degradation, resulting in lower crop land production [9, 21].

According to Tesfaye [69] and Million et al. [44], the
Hararghe highlands, for example, were characterized by heavy population pressure, steep slopes, severe soil erosion, and low productivity. Similarly, land in the South Gondar Zone was extensively deteriorated as a result of significant population pressure, and resource competition between crops and stocks resulted in low farming efficiency [35, 81].

The government and citizens have a duty to conserve the environment, according to FDREC Article 92.4 [18]. One of the systems for addressing the issues and maintaining crop productivity was watershed management [12]. Watershed management was the entry point for people, land, water, and biomass through the active participation of groups through mass mobilization [43]. Watershed management (WM) was the hydrological, sociopolitical, and ecological entity that supplies life carrying services to the rural community $[75,61]$. 
Watershed management was publicly launched in Ethiopia in the 1970s, with a focus on the highlands, where several SWC practices had been adopted via MoA [12, 44, 61]. Its goal was to open up new possibilities for reversing land degradation [43]. It also aims to guarantee the watershed's long-term management of natural resources [81]. Thus, the benefits obtained from those practices were ground water revived, soil loss reduced, degraded land renewed, and enhanced farm incomes and food security where the WM practices were appropriately applied $[12,24]$.

Until the late 1990s, however; there were some problems in the large scale efforts that remained insufficient due to execution that was top-down linear loom and incentive stand (Food-for-work), and lack of community based participatory WM. It also focused on reducing soil erosion rather than increasing crop land productivity, and it was not effective and sustainable (the 1970s-1990s) [24, 38, 81]. As Faysse and Ben Mustapha [17] and Samuel et al. [61] stated that the initiative was weak, largely owing to the low level of the notice given to the rural households' perceptions and interests.

As Mekonen et al. [43] and Daniel [12] stated some of the major limits of WM were lack of consciousness among policy makers, capacity-building training, and financial incentive restraints. Moreover, the World Bank [78] stated that the majority of the watershed targeted by Ethiopia for tackle and degradation was cited in regions that had a low capacity to adapt to climate change. Due to lax, Ethiopia faces the world's worst soil erosion. It is estimated that $95 \%$ of Nile River sediment originates from the Ethiopian highlands [70].

The government is required to promote public initiatives in its development efforts under FDRE Article 89.6 [18]. The EPRDF's leadership regime has pioneered novel approaches to watershed management in the first decade of the twentyfirst century, including as community-based integrated watershed development. Since 2012, the regime has boosted community-based participatory watershed management (CBPWM) practices and collective action aimed at crop land efficiency [24, 44, 61], where people jointly apply SWC and water harvesting (WH) practices [70]. At a time, large watersheds thus moved to smaller watersheds [25].

Those practices were carried out by a campaign, which seeks to cover a large area in a short period to diminish costs [61]. The campaign can be exciting, but it's provoking and ineffective for the reason that it is as a rule only done as soon as the effort has failed [64]. This keeps converse with society, and lowers the blockades against action, and increases the incentives to take action [28].

However, campaigning exploits the close up of the participants, not their knowledge and cognition [64]. As Samuel [62] said, community-based watershed management (CBWM) would not have sustainable effects on the livelihoods of farmers without empowering them in Ethiopia. Therefore, arranging training at various levels was critical for campaign-based watershed management practices [66].

As physical ability (watershed management) was wider and harder to act as a one man island game, collective action (CA) had to be linked with cognitive abilities such as social capital and orientation [22]

Collective action papers favor incentives. As noted by Olson [50] and Berhanu et al. [8], incentives must be selective in the sense that non members can refrain from any picky advantages. Since 2007, it has been known as "Farmers' Development Groups" in Ethiopia [16].

In this milieu, some WM committees attempted to provide political solutions to collective action concerns in violation of Article 78.5, then issued warnings to farmers in the bonded social capital: Debo, Jigge, Wonfel, Epub, Edir, and so on, which were governed by customary law [18]. However, as Choma and McKeown [11] argued, inter group calls could alert group members to partake in collective action. Fekadu [20] stated that the state political system was a source of tackle to the smooth running of customary laws. These committees are intended to guide farmers, but as a rule, they resort to force to partake in a program [61]. For this, as Alem-meta and Singh [4] and Birhan and Assefa [9] noted, farmers' training endorsed awareness and venture in land management practices. Liang et al. [39] and Muluken and Maria [45] also reported that farmers who joined farmers' training centers (FTCs) training were more active when they took action.

Farmers' willingness [61], the logic of [50, 59, 79], and participation in collective action [7] have all been examined by several researchers. However, research on farmers' cognitive abilities and their relationship to physical abilities has been sparse. As a result, most farmers consider WM as the only responsibility of food-for-work (FFW) households because they are compensated for it [77]. As they were not encouraged by the economic effects due to the lack of benefits from haring systems [61]. Others were reluctant to spend much time and skill to ensure the safety of the most vulnerable farmers [4, 67]. Farmers had also opened a worrying approach to collective action as the months got ready for public campaigns and thus cognized a program in which they were poorly initiated [61]. This implied that collective action in the Ethiopian highlands was not going to gun down its target.

This compelled us to incorporate new concepts, techniques, and organizational forms into our practices, as well as the institutions and regulations that would impact their behavior and performance [76]. Information is "input" into our minds, stored in our memories, and processed as thinking, and then acts as the foundation for "outputs," bodily activities. Its outcomes allow us to be under control the environment [23].

A similar study conducted by Wilson et al. [80], David [13], and Freeman et al. [22] stated that in socio-ecological settings, people's cognitive abilities such as social intelligence and general capacity to learn in groups, or teams resolve collective action problems. Cognitive ability affects the actors' behavior and success in strategic interactions [13]. This meant that cognitive ability may be used to predict how well a watershed is managed.

If farmers rebut to act collectively on a basis, the cognitive question would be major, which may affect the emergence and performance of collective action [42]. Thus, the main gap between the pieces of literature was: 1) missing the effect of 
cognitive abilities on watershed management. That ability over lie via each other and work as one as bits of information come in to the brain are processed, and acts ahead [14]. These pieces of cognition arrange people for collective action [37].

2) There were partial studies on how ample participation would not be actual without cognitive. As Sonmez [65] stated, in any specialized field, cognitive could be used to solve the trouble in the field. 3) Cognisance was yet considered only as the domain of academic areas and departments of philosophy and psychology, missing its role at the rural household level.

As Kim et al. [36] stated, in the workplace, cognitive assistance to memorize group goals and heed to make links between old and new information makes collective action successful.

Collective orientation, which was done via the quick group draft [40], was used to disseminate the campaign. In a cognitive tip, however, an emotionally stable path out performs learning quickly [13]. Farmers' decisions to participate in collective action may be influenced by this. As Sverker et al. [67] reported that problem-solving ability would be tired due to limited cognitive effects resulting from intellect decision-making. However, the study of cognitive collective action in farmers did not set much mind. The paper thus reviewed collective action in terms of the cognitive view in campaign-based watershed management practices.

\subsection{Objectives of the Review}

\subsubsection{General Objective}

Reviewing farmers' cognitive of collective action in campaign-based watershed management in the Ethiopian highlands

\subsubsection{Specific Objectives}

To see how cognitive abilities affect watershed management

To find out if there are any links between cognitive and physical abilities.

To investigate how experimental games influenced actors' interactive decision-making in a group setting.

To find out what factors influence farmers' decisions to take part in collective action.

\subsection{Reviewer's Questions}

What impact does cognitive ability have on WM?

Are there any connections $\mathrm{b} / \mathrm{n}$ mental and physical abilities?

What role do experimental games have in collective action?

What factors influence farmers' decisions to join CA?

\section{Literature Review}

\subsection{Concepts and Theories}

\subsubsection{Critical Review of Land Degradation}

The land consisted of landscape, soil cover, and water basics such as lakes and rivers, which lived on land, meaning the term was above soils. In thinking of land degradation, the terms land and soil would be used synonymously, since degradation processes were influenced both in the like way $[47,78]$. The degradation of land and soil means the loss of both functions $[15,58]$. Land degradation was defined as any fall or loss of the biological or economic productive capacity of the land resource base caused by human activities worsened by natural processes and often magnified and closely knotted with climate change and biodiversity loss $[73,75]$. The gap was there were no academically and frequently recognized definitions of land degradation, though some scholars had to adult their own concepts and theories. Therefore, scholars had to meet and come up with solutions.

Watershed review

A watershed is a region of land that drains all streams and rain to a common passage, such as the outflow of a basin, the mouth of an inlet, or any point along a stream channel [78]. A drainage basin's split was previously referred to as a watershed. A drainage basin, or catchment area, was so named after a watershed [73, 75]. There are five types of sorting systems, such as

Macro-watershed ( $>50,000$ hectares),

Sub-watershed (10,000 to 50, 000 hectares),

Milli-watershed (1,000 to 10,000 hectares),

Micro-watershed (100 to 1, 000 hectares) and

Mini-watershed (1 to 100 hectares) [34, 35, 71]

As well, watershed referred to the up keep regeneration, and the use of all-natural resources and humans in a picky watershed [61]. The Watershed was a hydrological, socio political, and ecological unit that fit the major role in determining economic safety and giving life carrying provisions to the rural community $(75,78]$. It is crucial to achieve maximum production with minimum hazard to the natural resources and the welfare of people in which an agreement should be carried out [78]. However, the productive standing of the watershed could be affected by human and animal activities as well as the upstream may affect the downstream [66, 75]. Thus, the rational cure of each of the interacting communities with their own subwatershed standing for micro-watersheds was needed. As Thorat [71] and Sverker et al. [67] shored-up that the downstream actors in the watersheds who were upsetting the pollution and flood would be able to convince the upstream polluters and conservers to modify their behavior.

\subsubsection{Watershed Management Critical Review}

Watershed management was a phrase used to describe the process of land use practices aimed at preserving and improving the quality of natural resources in a watershed by controlling their usage in an inclusive manner [71, 75]. In Ethiopia, watershed management was classified as soil and water conservation (SWC) practices [35]. According to Liang et al. [39], capturing the full paybacks from watershed-level investments required social capital and collective action, financial and technical support, and corresponding household investments. Watershed management entails the in charge use of natural resources with the active engagement of 
institutions, organizations, and individuals in a manner that is compatible with the ecosystem $[54,61,71]$.

This implied the careful use of all the resources such as land, water, and vegetation in an area to all aviated drought, moderate floods, prevent soil erosion, and improve water availability and increase food, fodder, fuel, and fiber on a sustained basis [54, 61]. As Kidane [35] stated that the task of WM included the treatment of the three main components such as land, water, and biomass by using the most apt biological and physical measures. Therefore the management work in watersheds must be socially, economically and environmentally all right $[62,71]$.

\section{Outcomes of watershed management review}

Soil, water, and vegetation were the most vital natural resources and watershed affected each of them [71]. Addressing key externality associated with watersheds was decisive for asset sustainability [75]. Besides, Kidane [35] noted that sustained productivity of food, fuel, fodder, fiber, fruit, and timber should be sure in effective management of soil, water, and vegetation. A watershed had thus a wideranging result on the lives of the people. One of them was it fastened balancing utilization of soil and water resources between upstream and downstream areas for productivity and protected land against all forms of soil deterioration, rebuild eroded soil, maintains soil fertility, stabilizes flood areas, conserving water and soil, and providing irrigation [71]. Thus, it could decide the social and economic safety and supplied survival carry services to the farmers [75]. Hence, watershed management carried out a campaign to meet its cited objective had to be done via collective action.

\subsubsection{Critical Review of Collective Action}

As the FDRE Constitution, Article 31 stipulates every person has the right to freedom of association for any cause or purpose [18]. Beginning with the work of Olson a body of theory was highly developed, and the concept of collective action had been cultured by various academics [19, 67]. In theory and practice, collective action has shown the failures of many of the rural development drawn of the 1960s and 1970s [2, 41]. Collective action is defined as the coordinated behavior of groups with a common purpose [19, 52, 59]. According to Holzinger [30], collective action is defined as the mutual action of a number of persons that intended to achieve and distribute various benefits via co-ordination. As Sandler [63] conceptualized, collective action is aroused due to the efforts of two or more people.

Collective action, on the other hand, did not result in longterm renovation [16]. Distribution, defection, coordination, dispute, and instability were all issues in collective action [30]. It wasn't automatic, and it focused on specific attention when people expected more [42]. People's expectations influenced mental image processing [23]. Individual actors benefited more from egotism (defection) than collective players, which discouraged cooperators [67]. Without adequate preconditions, such as group orientation and individual cognition, it would be ineffective [74]. According to Sonmez [74], collective orientation was raised and altered through an actor's inward complexity as well as the actor's relationship with the environment.

Moreover, Ostrom et al. [52] claimed that trust, reciprocity, and reputation were mood determinants influencing a person's cooperative conduct in a group setting. People develop a reputation for being truthful. Anyone's cooperation was contingent on conformity to the norm [27]. As noted by Sverker et al. [67], heterogeneity poses a cooperatively means risk. According to Holzinger Van [30] and Getachew et al. [26], collective action problems can be solved by reciprocal altruism, norms, attention, associated strategies, collective decision-making, and authorizing with political, motivational, and rational expectation solutions.

Social capital in collective action

"The common knowledge, norms, rules, understandings, and expectations about the patterns of interactions that groups of persons bring are present activity," as defined by social capital [52]. Where social capital was included as a decisive variable in the collective action definition, it was not always evident [42]. Nonetheless, a study conducted by Fekadu [19], Getachew, et al. [26] and the World Bank [78] stated that where communities were typified by close social proximity, collective action was apt to be achieved. Besides, social capital as networks facilitated interactions between individuals [26]. Social capital in collective action aimed to lower transaction costs of exchange, reduce the cost of enforcing rules in the provision, and underpin local authority recitals by sketching them into networks [8]. Further, social capital is quantified by contacts, trust measures, strength of networks, group membership, degree of civic engagement, and violence [42]. However, it was hard to measure directly similar to collective action. Therefore, proxy indicators were crucial.

Physical capital, human capital, and social capital are the three inputs that provide economic rewards. Physical capital, for starters, refers to the material resources that are utilised to accelerate the flow of future income. Human capital, on the other hand, refers to the knowledge and abilities that people employ in order to solve challenges. Third, social capital enables the use of tacit knowledge and human capital as a spirited gain tied in product development $[23,52]$. Even if it benefits individuals, social capital is a community-level concept [23]. Nonetheless, thus social capital can influence both human capital, and physical capital [39, 26].

The three types of social capital

Bonding social capital: As Kitapc [37], Liang et al. [39] and Getachew et al. [26] stated, it was a link between people who were close friends, and family. Likewise, Njuki et al. [48] defined it as closed networks of friends and relatives among a social group in a localized community. Thus, it was a network prepared for close ties with family, friends, and neighbors that assisted people to get in times of calls. In Ethiopia, for example: Debo, Jigge, Wonfel, Edir, Eqube, etc.

Bridging social capital: Linked networks require team work with other external groups to achieve set goals; for example, it could be the link between two local groups from diverse villages. There were five signs of social 
capital (networks, reciprocity, trust, norms, and social agency) [48].

Linking social capital: It was the meeting of local groups with institutions or agencies in higher influential positions [48]. Kitapc [37] defined it as the "norms of respect and networks of trusting relations between people who contact local government. Likewise, Liang et al. [39] and Getachew et al. [26] stated that it was a system for pulling resources from formal to informal institutions for the safety of the people. Thus, as it is a network between community residents and leaders of institutions, it helps people to exercise their rights and control resources.

\section{Theoretical model (Experimental game)}

There is cooperation game between two farming people villages. The links between two local groups from unlike villages intend to reciprocate support activities in Ethiopian highlands that have most likely shared land degradation that entails watershed management in the course of collective action. Bridging social capital at this instant serves as a bridge between different bonding social capitals. Trust and reciprocity, hence, provide hub links between networks and collective action. Nonetheless, trust is, of course, an easily broken concept given those members have to be able to suffer from doubt about the other members' perceived motives, and actions that affect reciprocity. When trust comes to team members, thus "action speaks much louder than words".

A game at this point signifies a strategic form and an extended form where the second shows these rise of moves unlike the earlier. Please, look at a simple game:

Table 1. Strategic form of cooperative game.

\begin{tabular}{|c|c|c|c|c|}
\hline \multirow{4}{*}{ Village-1 } & & \multicolumn{3}{|c|}{ Village-2 } \\
\hline & & $\mathbf{A}$ & $\mathbf{O}$ & Where, $2>1>0>3$ \\
\hline & A & 1,1 & 3,2 & \\
\hline & $\mathrm{O}$ & 2,3 & 0,0 & \\
\hline
\end{tabular}

Source: Adapted from Fekadu [20]

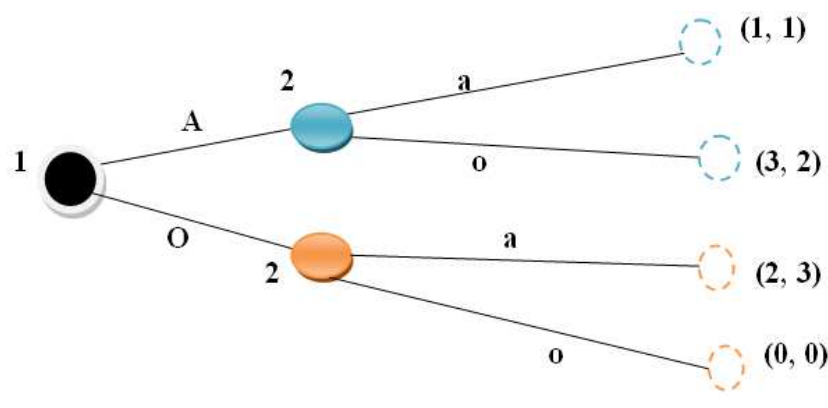

Figure 1. Extended form of cooperative game.

Simplicity on the simple game

' $A$ ' is 'Allow' and ' $O$ ' is 'Oppose' strategies

The two pairs of strategies produce four possible outcomes; stand for the four pairs of numbers, called payoff pairs.

$(1,1)$ If both players allow to cooperate

$(3,2)$ If player-2 allows and player-1 opposes

$(2,3)$ If player-1 allows and player- 2 opposes
$(0,0)$ If both players oppose to cooperate

$(1,1)$ Nash equilibrium: In this, each player's strategy is best when considering the decisions of other players. Every player succeeds since each gets the outcome they wish.

Experimenting with the game

Assume that villagers in villages 1 and 2 have expressed concern about land degradation, which has resulted in decreased crop land efficiency, jeopardizing their livelihood security. As a result, they have created a contract to assist each other, which are referred to as negotiation. This is preferable to mediation (unbinding third party intervenes), arbitration (binding third party intervenes), and litigation (binding third party intervenes in court procedures), on how to protect both people fairly and effectively. Negotiation processes were viewed as sequential games shaping reciprocal access [20]. Watershed management rooted in a campaign was supposed to waste two months per year. Both village envoys agreed to take action collectively, according to an unwritten agreement between them.

The reasoning is that land degradation is more widespread, complex, and difficult to manage by a small village is more likely to involve other communities. Thus, they divided two months, eight weeks, and then alienated 8 weeks 16 working days; each village has thus taken on the responsibility of collectively carrying each other as well owed 8 working days for village- 1 area and 8 days for village- 2 area. Nonetheless, heterogeneity poses a threat to cooperation systems, particularly disparities in identities, socioeconomic status, cultures, and faiths [67]. It is not just a varied society with diametrically opposed socio-cultural backgrounds, but also a homogeneous society with the ability to act collectively due to private benefits.

Recognize that the contract is based on customary law (informal rules of the game). These informal, often unspoken norms wield equal or greater authority than official rules [33].

If there is a gap, the parties will enlist the help of other community elders, which will save time, resources, administration, and traveling costs. Mediation and arbitration, rather than litigation, are informal systems in which a third party intervenes.

The early neo-classical institutional economics considered the contract as a raise to remain transaction costs, as North and Thomas [47] and Meinzen-Dick et al. [42] noted.

However, in the absence of outer pressure, some members in a community who would benefit from teamwork will refuse to cooperate, implying the need for social capital. Because Matrix games are instantaneous, players cannot see what strategy other players like, so there is no a pragmatic theory [30].

If both players work together, they will each receive a payoff of 1 or payoff pairs $(1,1)$, which will increase the villagers' trust, reciprocity, and reputation. Golden-Rule ideas such as "Do unto others as you would have them do unto you" and "Hurt no one so that no one may hurt you" [21] characterize reciprocity in different cultures. "Do unto others as they do unto you," however, was part of the reciprocal altruism idea, although it wasn't precisely the Golden Rule [41]. This indicates that life is a feedback loop in which we 
receive what we give. It is one of life's most appealing rewards that no one can help another without first benefiting himself. As a result, this is a win-win situation, but the big issue is how to keep it going.

It will be pure altruism if player-2 stays on track, if player1 adopts a dominant strategy, reducing its partaking days. Altruism is defined as behavior in which one continues to cooperate despite the failure of a rival to reciprocate [20]. According to McElreath et al. [41], altruism, or action that reduces an actor's individual fitness while increasing the fitness of another person, has drawn a lot of attention from academics since it appears to contradict both natural selection and normal preferences. As a result, player-1 becomes a single recipient, requiring a payoff pair $(3,2)$. The cooperator is the one who gets the lower wage. As a result, an institution's incentive to defect is critical.

In such a setting, Fekadu [20] claims that the players' ability to predict the collective benefit of collaboration influences their decision to allow or deny the right of entry. Player-1's activity is motivated by self-centeredness, forcing player-2 to break the contract that will penalize each other. The GIGO concept, as used in computers, appears to be: garbage in, garbage out, and negative in, negative out. This then takes it back to reward $(2,3)$. As a result of its pathdependence, it is projected that player-1 will lose reputation. As Gudeta [27] emphasized, an individual's gain is based on their ability to be trusted with the norms that are believed required for people to cooperate. As a result, institutions should manage a penalty and broaden the extent of their unification.

If both players stop collaborating, the game will come to a halt or end $(0,0)$. As a result, there is a principle known as "no war, no peace." Even though they have a contract, they do not work together. The rationale is that strict rules of the game are required to enforce the contract between the two parties. As a result, the institution plays a crucial role in shaping how people interact with one another [23].

In theory, the worst mistake a village can do is to repeat it; thus, player-1 learns from its mistakes and subsequently returns to cooperation. If this criterion is met, then a "tit-fortat" strategy will incentivize the reduction of antagonism in any event [20]. Coordination may not even be intentional, as Njuki et al. [48] \& Johann et al. [23] pointed out, coordination may not even be purposeful, but rather the result of people following social rules and conventions.

Altruism, standard, attention, connected strategies, shared decision-making, external power, and sanctions were some of the collective action issues that were identified. However, hope solutions that were political, motivational, and rational were critical [30]. As a result, increasing the power of informal institutions to enforce the contract and lowering the tensions between conduct that helps a village and action that benefits the community are critical.

Operationalizing collective action

The two challenges that confused the concept of collective action was spatial scale (spatial distance) and temporal scale (temporal distance) analyses, as well as quantitative and qualitative techniques [67]. For starters, because collective action is a dynamic activity involving social relationships, which is one of the cognitive abilities, it is hard to quantify. Thus, proxy indicators are employed. Nonetheless, it was challenging to identify comparable metrics across study periods because the signals of collective action (CA) varied via time and across cultures and communities [42].

On a spatial scale, collective action research required taking into consideration both social and resource units, which typically differ [8]. Thus, the purpose of this article is to discover the factors influencing farmers' decisions to join in CA, which demands many units of observation \& analysis: resource, community, and institution features. Berhanu et al. [8] put it to the test. In numerous researches, methodological techniques have an impact on the concept of collective action.

Traditional economists' assessments tend to concentrate on the precise motivations of individuals to engage in collective action [50]. Sociologists, on the other hand, tend to analyze group behavior and how motivation for action is shared via social networks [8, 67]. Thus, bringing different disciplines together to combine methodologies is an option. It is possible to consider both quantitative and qualitative techniques when collective action is required at the community level.

\section{Institutional Analysis Framework}

The Analytical Framework (AF) is a simplified form of the Institutional Analysis and Development [54], with three main components (initial context, action arena, and outcomes). The analytical framework for natural resource management consists of three characteristics: resource, user groups, institutional arrangement, and the environment [2, 42]. How do these characteristics influence actors' collective action behavior? They are independent variables that affect CA in the action arena, as shown in Figure 2.

As a result, various actors bring their logical thinking, assets, knowledge, and motives into an action arena where collective action is taking place with the goal of reducing land degradation via watershed management (WM) practices. At this phase, success is determined by the interactions between traits and the action arena.

Please take a look at Figure 2.

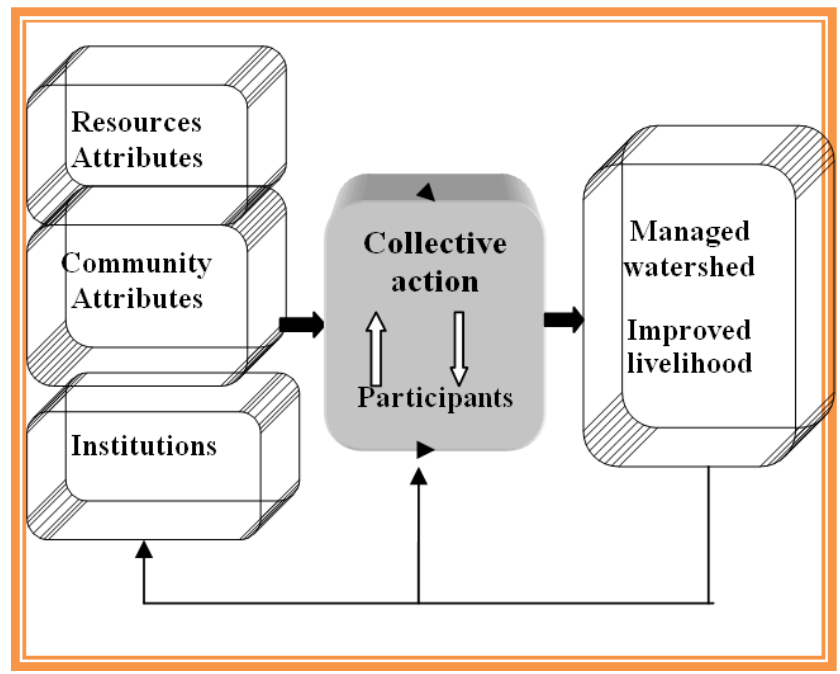

Source: The IAD adapted from Fekadu [19]

Figure 2. Analytical framework. 


\subsubsection{Critical Review of Cognitive (Cognition)}

Cognition is derived from the Latin expression cognoscere, which means "to know" or "to come to know." As a result, cognition encompasses the activities and processes involved in the acquisition, storage, retrieval, and processing of knowledge, as well as our ability to perceive, attend, remember, think, categorize, reason, and make decisions [67].

"All processes by which sensory input is modified, reduced, detailed, stored, recovered, and utilized" is what cognitive psychology relates to [23]. In other words, cognition is the process of acquiring and controlling knowledge, and it is a reflection of being rational because it is the act of knowing/thinking. It isn't visible, but it can be deduced [10]. In addition to attention and concentration, processing and interpreting information, problem-solving, and decision-making, cognition encompasses the ability to prefer, understand, memorize, and apply information [67].

Psychologists discovered that the mind, like a computer, could be considered as a device that signified and corrupted data. The metaphor of the mind as a computer was born. As a result, computers have accelerated the adoption of information processing [23]. Cognitive theory is primarily concerned with the interaction and coordination between mental workings and the information processed through this complex network [14]. People created cognitive make-up as they were taught that determined their notions of the natural world and the environment [67]. Processing information, developing understanding, applying knowledge, and solving crises are all examples of cognitive mental processes [65].

There are six levels of cognition, according to Ramalingam et al. [57] and Hoque [31]: knowledge, comprehension, and application, analysis (logically splitting up information), synthesis (making something new), and evaluation. The more higher the level, the more complex the mental act becomes. Higher levels are unnecessarily more desirable than lower levels, because higher levels cannot be obtained without the ability to use lower levels [10]. Learning abilities associated with higher-level processes were also fixed in lower-level learning kills processes [57]. As a result, this should progress from easy to difficult. As Hoque [31] pointed out, the greater one's level, the more practical the skills/ activities are in daily life.

\section{(i). Cognitive Domain}

Benjamin Bloom, an educational psychologist, classified what and how humans learn into three distinct domains: cognitive, affective, and psychomotor learning [31]. However, according to Sonmez [65], there are four types of learning domains: cognitive, affective, psychomotor, and intuitive. This work focuses solely on the cognitive domain so it exclusively deals with the development of intellectual skills, focuses on content knowledge and intellectual skills (cognitive outcomes) rather than context, and is emotion-free.

Table 2. Sonmez's model of learning domains.

\begin{tabular}{llll}
\hline Cognitive domain & Affective domain & Psychomotor domain & Intuitive domain \\
\hline Perception & & & \\
1. Knowledge & 1. Receiving & 1. Excitement & 1. Recognizing \\
2. Comprehension & 2. Responding & 2. MakingManuelControl & 2. Discrimination \\
3. Application & 3. Valuing & 3. Skill & 3. InsideBorn \\
4. Analysis & 4. Organization & 4. Fittingsituation & 4. RetentionunderControl \\
5. Synthesis & 5. Characterization & 5. Creating & 5. Future-pastRelationship \\
Evaluation & & & \\
\hline
\end{tabular}

Source: Sonmez [65]

\section{(ii). Cognitive of Logic}

The study of the concepts and methods of proper thinking is referred to as logic [68]. Logic is a branch of thinking that includes recalling, inferring, picturing, and freely associating. While all reasoning entails thinking, not all thinking entails reasoning [68]. Whatever view, position, or opinion we hold, logic gives a solid foundation for it. It allows us to develop a more critical mindset and spot common mistakes [32]. For a high-quality strategy and to manage the $\mathrm{HH}$ or community benefits in the watersheds, reasoning is required.

Reasoning is a type of thinking that involves resolving problems, making inferences, and drawing conclusions [68]. The term "reasoning" refers to a structured chain of ideas. Reasoning is a mental shift in which some ideas serve as a foundation for the development of others. Logical reasoning or critical thinking [57] is terms used to describe high-quality reasoning. To learn or better, logical reasoning can be applied. Every learner has the ability to reason clearly, and everyone can take a step forward [31]. The usefulness of logical reasoning as a tool for making good judgments about your own life, as Taiwo [68] emphasized, is in the decision.

\section{(iii). Cognitive Skills}

Cognitive skills allude to the picking up of wide mental or cognitive competencies. As Ramalingam et al. [57] and Hoque [31] expressed that there were six levels of cognitive abilities such as information (the capacity to review), comprehension (capacity to appear a essential understanding), and application (capacity to apply to a unused work), analysis (ability to break up data consistently), blend (capacity to make something unused in an inventive way), and evaluation (assess convenience or adequacy). Lower levels murders connected with higher-level forms [13]. As Hoque [31] expressed that when one moves up into 
higher levels, the more applicable the abilities required in lifestyle. Cognitive abilities, in this manner, foresee work execution; teach that progress work presentation might moreover progress cognitive skills [13].

As Wilson et al. [80] expressed that participation might create cognitive activities: recognition, attention, memory, and logical reasoning, with physical activities such as chasing, gathering and battling. This could be surveyed by verbal and numerical capacities, problem-solving, theoretical, basic and vital considering [13, 31]. Cognitive skills are come on as of cognitive activities: perception, attention, memory and logical thinking indeed in the event that it is in situation. These are mentioned as follows:

Perception is the kind of what is sensed. The physical events conveyed to the retina may be interpreted as a selective color, or shape. The physical events chosen up by the ear may be taken as sounds, a human voice, and so forth [80].

Attention: the process of perception is greatly affected by attention, a fact that grips pulling of arriving stimuli. People perform not pay attention to everything in their environments; nor do they attend to all the stimuli imposing on their sense organs. More willingly than becoming besieged by the huge intricacy of the bodily world, we concentrate on some stimuli and do not become aware of others [36]. However, since attention skills are considered higher-level skills such as memory and reasoning, people with concentration troubles frequently confirm symbols of other cognitive problems. One of the signs is trouble closing work on more than one task at a time, and restiveness, and being easily troubled [13, 80].

Memory is defined as the capacity to carry on information in the end. It is the process by which knowledge is encoded, stored, and later retrieved $[13,68]$. It is essential to any information processing system since it overlaps the ability to learn. However, if there is incapable in learning from its mistakes would perish a dynamic real-environment [23]. In which cognitive researcher sought to focus on the findings of the practicability of separate memory systems, how these memories interact, features of these individual memory and how long information remains viable in a memory system; capacity, as well as how much information the memory system can hold and coding to the picky information, the system contains $[23,80]$.

Logical reasoning/critical decision-making is the course of through a levelheaded, orderly cycle of steps based on sound arithmetical dealings and given articulations to reach at a conclusion [31]. In rationale, deductive thinking $\&$ inductive thinking are the two ways of getting a conclusion. Finding begins with a wide truth, such as the articulation that 'all men are mortal', a precise word that 'Socrates may be a man' and a conclusion follows: 'Socrates is mortal'. In inductive thinking expansive conclusions are faded as of specific observations; information lead to conclusions [57, 80]. Be that as it may, cognitive aptitudes may be misplaced and harmed. In this manner, a cognitive remedy was treatment to development abilities and had two key looms: remediation and compensation. The previous concentrated on improving skills that had been misplaced or harmed. The last mentioned one helped individuals to memorize to utilize assorted ways to attain an objective [36].

\subsubsection{Conceptual Framework}

According to Abafita et al. [1], market orientation enabled farmers to obtain symmetric knowledge regarding market signals throughout the commercialization of agriculture. The former study, on the other hand, obscured the market orientation by focusing solely on market participation. As a result, it was more apt to assess the impact of orientation on participation, with the conclusion that orientation was found to be a powerful underpinning of farmers' participation.

The umbrella of all validated variables that affect farmers' decision to participate in collective action in this study was cognitive. Human capital can be leveraged for collective participation through social capital.

The collective orientation that was based on internalized explicit knowledge, tried to increase collective participation. According to Sonmez [65], the internal complexity of actors and their relationships with the environment raised and transformed collective orientation. It also encourages farmers to consider when and where they should utilize those actions [72]. Collective orientation, on the other hand, was halted by quick mass mobilization, which had an impact on farmer awareness [40].

Due to a lack of attention to cognition (cognitive), farmers did not internalize the benefits of collective action [68]. Farmers were well-trained and disciplined to journey to collective participation as a result of human capital (tacit knowledge) and collective orientation (explicit knowledge). Participation is the sensible labor that people do to support a community of practices around them. Participants are vital to reorganize themselves in order to contribute to the labor involved in practices [2]. Collective action's goal is to prevent land degradation. It was the predetermined effort that people perform in order to carry out activities, whether these are new hard interventions [63].

Collective action here is a dependent variable that is influenced by explanatory variables and requires investment. Social capital is built over time, yet it can be quickly depleted, i.e. Trust. It is difficult to replace if it is lost because it is the outcome of a conscious effort. As a result, cognitive provides insights into the creation of effective social capital derived from mental processes that occur as a result of regular contacts [37].

The cognitive dimension refers to members who have a common understanding of the team's collective orientation and mission [39]. As Pugel et al. [55] pointed out, farmers benefit from shared understandings of a collective orientation. One of the most vital prerequisites for the formation and expansion of farmer collective action is collective orientation [74]. According to Liang et al. [39], having a strong basis in cognition allows social capital to assist members in acting collaboratively. Preparation breeds confidence, thus paying more attention to the inputs of collective action give support to knowledge exchange and success.

As a result, please take a look at Figure 3 for a conceptual framework. 


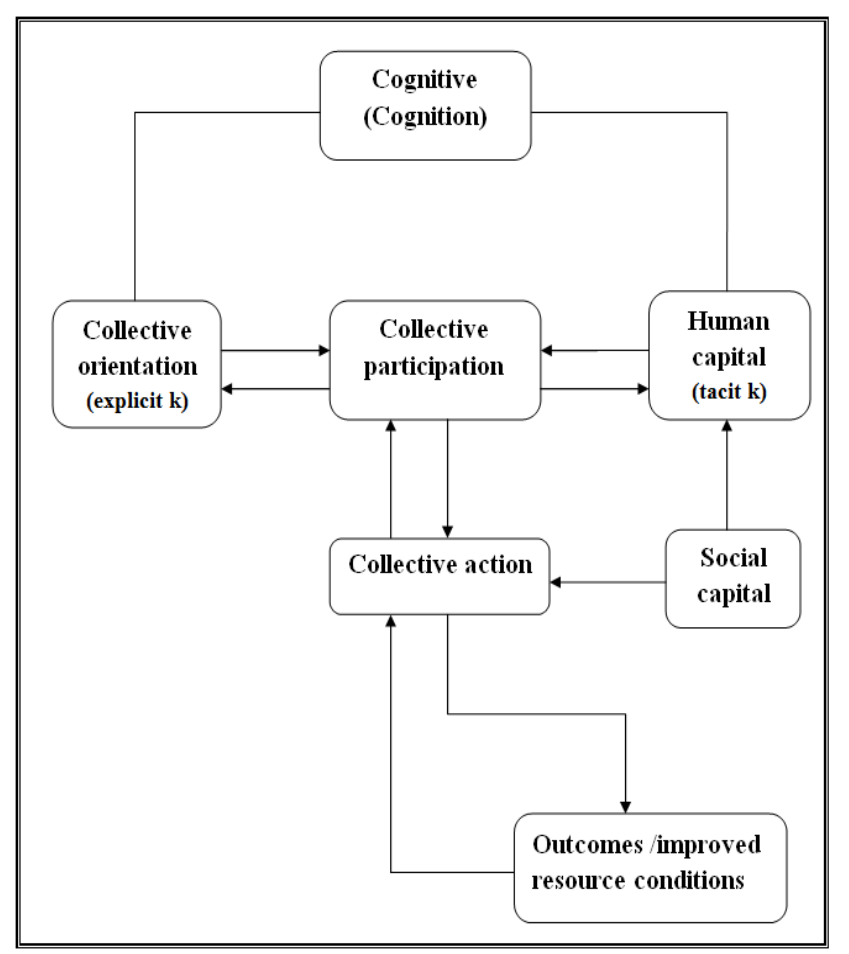

Figure 3. Conceptual framework linking the structural variables.

Source: Adapted from Sandler [63], Kitapc [37], Sonmez [65] and Sverker et al. [67]

\subsection{The Assimilation of Cognition, Collective Action and Watershed Management}

Land degradation has reduced land productivity, making governance more reliant on collective action [22, 44]. Social capital (social bonds) and collective orientation (symmetric information) are two cognitive abilities that help groups or teams solve challenges through collective action. Because physical abilities (WM practices) are broad in scope and difficult to act on alone, collective action is vital. Collective action acted as a link between cognitive and physical abilities in this study.

"Farmers' Development Groups" have existed in Ethiopia as a kebele-level social movement organization from the first decade of the twenty-first century [16]. They shared two objectives: raising group awareness and organizing collective action for any development-related interventions [14]. As a result, membership in this organization could have a direct impact on collective action targeted at improving natural resource quality [16, 36, 61]. Similarly, Ramalinga et al. [57] claimed that cognitive research tends to focus on aspects of the complex and difficult interactions between humans and their surroundings. When difficulties could not be solved in person, as Fekadu [19], Roger [59], and Sverker et al. [67] emphasized, collective (group) action was indispensable.

Land degradation harmed land effectiveness in Ethiopia's highlands. Different systems, such as sustainable land management and watershed management (WM), were used to manage it appropriately. However, watershed management was selected since it attempted to protect and manage all natural resources. Integrated WM's objective was to provide information-based solutions to all natural resources and people, and it had forged a link between the regime and civil society and the private sector in order to achieve peak food safety and ecosystem fitness [24].

Collective action is frequently examined in the context of physical tasks like natural resource management. They had overlooked, however; the importance of cognitive functions such as perception, attention, memory, and decision-making [80]. As a result, it was critical to anticipate seeing farmers combining their wits and muscles. This implied that if the benefits of group action are bigger and the problems of land degradation are less for cognitive than physical activities, this is even more so.
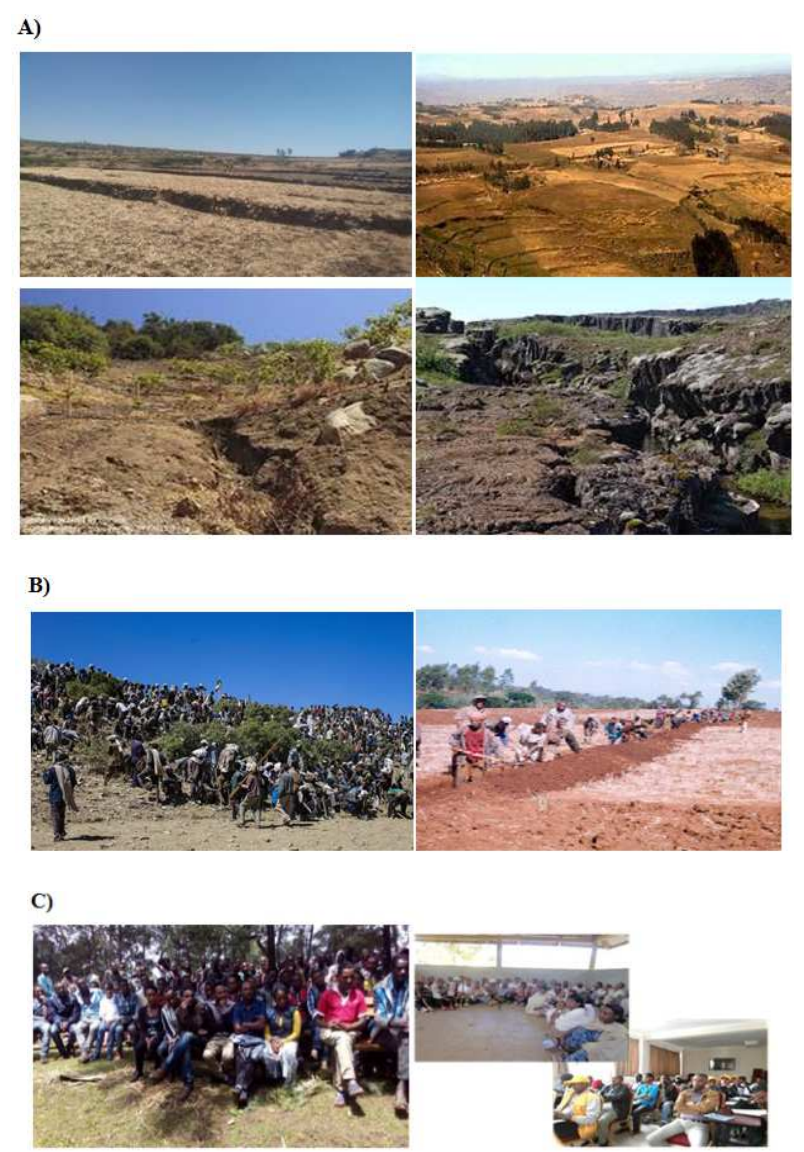

Source: Adapted from Google (2020)

Figure 4. Land degradation and public campaign-based collective action.

\section{Methodology}

\subsection{Overview of the Methodology}

The Ethiopian highlands, which were notably vulnerable to land degradation involving watershed management, were the focus of this review, as stated in the introduction. Although not unique in theory or practice, one of the topic's unique features was an emphasis on farmers' cognition prior to any physical tasks undertaken through collective actions. In the year 2020, Web Science would be used to search for published articles using a combination of key phrases and synonyms.

The reviewers then looked at open definitions of the key 
phrases from the previous subjects. Furthermore, the reviewer included certain scholars' works in this section, demonstrating how they used samples, methodologies, looms, and models to rationally induct and deduct their findings. Its goal was to investigate the methodological gap and then point future researchers in the right direction.

Ethiopia is a country in the Horn of Africa with a land area of 1.1 million square kilometers. It has a population of 109.2 million people. It is thus Africa's second most populous country [78]. The risk of falling into poverty remains major, especially for those who work in rain-fed agriculture [25]. Most people's livelihoods are still based on natural resources, which are vulnerable to climate change. To address these issues, the government completed GTP-I in 2015, a structural restructuring of the economy. Industrialization, urbanization, and export support are all priorities in the GTP-II (20152020) [25]. The GoE has altered its mind on moving to a private-sector-led project [78].

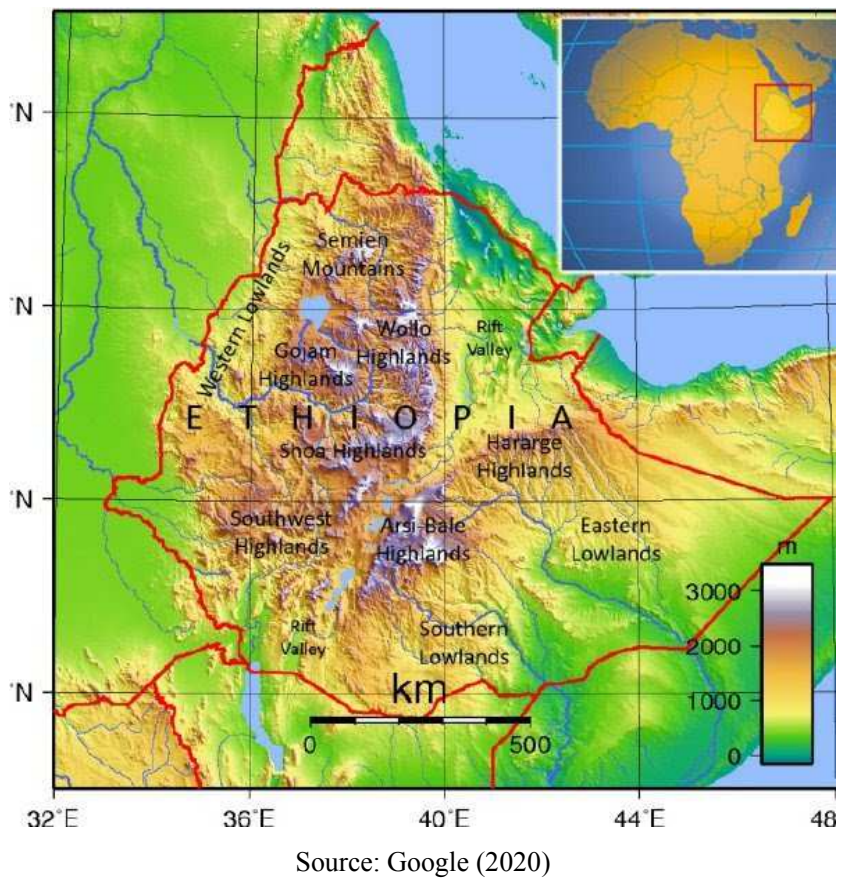

Figure 5. Physical map of Ethiopian highlands.

\subsection{Methodological Reviews}

\subsubsection{Watershed Management}

As far as we know, Million et al. [44] utilized a multi-stage sample technique in their study on Determinants for Adoption of Physical SWC Measures by Smallholder Farmers in Ethiopia. To begin, three districts were chosen at random: Deera, Gurugutu, and Haramaya. Second, three (3) kebeles were chosen with care based on the severity of land degradation. Households were then stratified into adopters and non-adopters of SWC. Following that, 400 adopters and non-adopters were chosen at random. In addition, $790 \mathrm{HHs}$ plot-level observations were gathered. Farmers' perceptions of newly introduced soil and water conservation measures were assessed using a semi-structured questionnaire. The factors affecting the adoption of the three (3) SWC measures were identified using a multivariate probit regression model. Birhan and Assefa [9] were both in favor of it. However, to test farmers' attitudes, a Likert scale is a possibility. My admiration, on the other hand, goes to the scholars who have employed both qualitative and quantitative methods to close gaps based on the objectives and questions they have set.

According to Samuel et al. [61], the study "Assessing Farmers' Willingness to Participate in Campaign Based Watershed Management" was conducted in the Bose District, which was chosen specifically because of the extent of soil erosion. The three rural peasant associations (PAs) in the district, Ararso-Bero, Sara-Areda, and Qachachule-Guja, were purposefully chosen based on their performances in the district's annual report. Primary and secondary sources of information are used to compile the data. KII, interviews, and structured questionnaire methods are used to obtain primary data. The Google Earth Engine provided secondary data.

Farmers' opinions of the watershed management program's outcomes are determined using descriptive statistics and oneway ANOVA. Farmers' desire to participate in the CBWM program was assessed using Cronbach alpha and Spearman's spatial correlation coefficients, which ranged from strongly disagree to strongly agree. The gap is assessing farmers' willingness to participate using a Likert scale and binary logit regression, as well as employing both approaches to pave the path to aptness devoid of gaps that neither strategy can fill, while it is conceivable to utilize a Likert scale.

\subsubsection{Collective Action}

Farmers' collective action organizations named "Farmers' Development Groups" were founded by the Ethiopian regime in 2007 based on the supposed shared interest of farmers and trust that would drive farmers to act jointly [16]. Fekadu [19] conducted the following study, Collective action in waterpoint management: Harshin, Kebribeyah, and Miso, three areas in Eastern Ethiopia were purposefully picked based on the extent of water scarcity for cattle watering. The information was gathered from both sources. Data was collected in two stages due to environmental variations and respondent availability: November 2004 to May 2005 and August to September 2006. FGD, KII, observation (field notes), and questionnaire were used to collect data. $160 \mathrm{HHs}$ were selected from eight kebeles based on water-point management actions, land size types, and mobility patterns. The method of qualitative data analysis was applied. The Implications of Group Norms for Adaptation in Collectively Managed Agricultural Systems is reinforced by research by Tozier et al. [72]. In addition, Pugel et al. [55] published a paper on Factor and Actor Networks: Alignment of Collective Action Groups for Water Sustainability in Ethiopia. They have exclusively employed qualitative research, which allows researchers to hypotheses and methodologies intend to the specific circumstances.

However, qualitative research necessitates the use of qualified workers to gather and analyze data on the spot. Different interviewers' interests can skew the results in this case. Meinzen-Dick et al. [42] support the idea that interview topics change frequently, making it difficult to compare responses from different interviews. It's also difficult to 
explain human behavior in clear, quantitative terms using this method. Furthermore, the data was gathered with a smaller sample size than usual surveys. My gratitude goes to the focus group discussion (FGD), which is a good way to collect data when we're trying to qualify people's viewpoints, behaviors, social-cultural norms, and initiatives in order to discover issues.

However, the reviewer believe that if the study considers the usefulness of the Likert rating scale and compares quantitative and qualitative data, it may not be as excellent as it appears, because the need for public goods is a function of both quality and quantity. As a result, both these analyses are more effective at collecting comparable data from a vast number of places to corroborate each other. Ankur et al. [6] and Liang et al. [39] were the ones who carried it.

The combination of approaches to utilize in the analysis of collective action is also determined by the research topic (s) [42]. Nonetheless, because qualitative analysis and data gathering are time-consuming and costly, this reviewer would want to combine the quantitative survey and qualitative focus group methodologies. Both are extremely similar, especially in the study of collective action, i.e. qualitative can be used to plan and interpret quantitative data, whilst quantitative data can assist researchers choose case-study sites for more indepth examination [42]. The goal of this article was to look at cognitive collective action in watershed control campaigns. The binary logit model can be used to figure out what factors influence farmers' decisions to participate in collective action (yes or no). Personality psychology arises to comprehend participation in collective action, as Duncan [14] suggested, and has uttered the individual difference variables important to group awareness.

The Alem-meta and Singh $[4,5]$ led research team also used the binary logit model in their research. As a result, even though it was possible to utilize both qualitative and quantitative approaches separately, my bias was employed both in the mix and as a reasoned in advance, resulting in a gap. This idea was confirmed by Etenesh's study [16], which found that when exhibiting, discussing, and analyzing study data, both qualitative and quantitative methodologies should be used.

\section{Conclusion and Recommendation}

In conclusion, the group's cognitive success is evident due to the merging of separate people. As a result, members must be picked based on cognitive ability. To do so, the effects of cognitive abilities on watershed management should be evaluated at each peasant association using their linguistic and numerical abilities; abstract reasoning, problem-solving, critical thinking, and strategic thinking in intellect, social relations and orientation. This aims to persuade them of how they have digested, internalized, and nurtured something new in collective action to combat land degradation, as well as logical and creative something new. To put it another way, those cognitive qualities improve a group's or team's ability to solve problems via collective action.

Farmers in Ethiopia's highlands are fighting over land degradation, which has resulted in the drying up of wells and springs and a decrease in farmland productivity. Watershed management (WM) is decisive for overcoming roadblocks and maintaining productivity. Because $\mathrm{WM}$ is so large and difficult to act alone on, collective action (CA) is critical. The regime has paid attention to it as a result of this. However, concerted action has yet to tackle the Ethiopian highlands' land degradation problem. It is due to a lack of attention paid to inequities in farmers' cognitive and physical abilities.

At each level of the regime to the pragmatism of farmers' cognition, there is also a lack of networked particular methods and practices for collective action and WM. As a result, the reviewer suggests that researchers and policy makers focus on the consequences of cognitive abilities on physical abilities in the future through collective action. They focus on combining physical abilities with cognitive abilities such as intellect, social networks and collective orientation (symmetric information).

Cognitive activities such as perception, attention, and decision-making are studied first, followed by physical activities such as SWC routines. To keep customary rules working smoothly and provide selective incentives, policy makers concentrate on developing both formal and informal institutions (rules-in-use). The government should focus on amending Articles 40.3, 40.8, 51.5, 52.2 (d), and 89.5 of the Federal Democratic Republic of the Ethiopian Constitution (FDREC) to protect property rights. Therefore, researchers can use the findings of this analysis to assist policies and extension initiatives aimed at advancing the uptake of future farmers' cognition prior to any physical intrusions in order to stimulate successful collective action.

\section{The Research Gaps}

Farmers' willingness to, logic for, and participation in collective action, as well as watershed management practices, have been investigated by a number of academics. Their motives were to reverse land degradation and improve rural households' lives in Ethiopia's highlands. They employed a variety of methodological frameworks to assess how motives would be realized. However, most of the studies that there viewer interpret relating to collective action were measured exclusively in qualitative ways without employing empirical models, because they reasoned that it could only be measured by proxy indicators (variables) like social capital. Using both qualitative and quantitative approaches to collective action was confusing, as indicated earlier in the methodology section. Collective action thus is significant for communitylevel actions, such as WM, which have a broader reach than acting alone, and some research uses the multinomial logit model in blending with other descriptive and inferential statistics for WM. This idea should be taken in to account.

This review looked at how farmers in Ethiopia's highlands cognize collective action in campaign-based WM. The most serious issue was a lack of direct access to topics for going over. Second, cognition is the process of collecting data or knowledge through learning, experience, or the use of our senses. It was seen as a psychology department and academic area notion rather than one applicable to rural development and agricultural innovation (RDAI) and farm households. 
The reviewer's motive at the time was to highlight the RDAI School's multi disciplinary nature and examine things from multiple angles.

Traditional economics and sociologists used various looms to collective action, which created gaps in the literature. The former was more concerned with incentives, whereas the latter required us to consider group behavior in order to participate in collective action. Thus, they must come up with solutions rooted in the community where they live, at the very least around the center.

The second gap was a focus on land degradation and its solutions, as well as physical ability and its outcomes, rather than the farmers' current cognitive abilities and activities, as well as the real situations. As a result, prior to any campaignbased interventions aimed at encouraging collective action in WM, farmers and their localities must be considered.

The third gap was that most cognition literatures [13, 22, $31,36,57,67,68,80]$ were unclear concerning words like cognitive domain, cognitive skills, cognitive abilities, and cognitive activities. As a result, those scholars must come together and develop at least be worthy of agreement on the phrases.

In collective action, the fourth gap was the use of the terms group versus team. A group is described as two or more people who have a stable relationship, share a common aim, and see themselves as a group [22,63]. A team is defined as a group of people with different abilities and activities that collaborate on a common project or objective for the purpose of networking and reciprocal carry [60]. Teams are groups that worked closely together toward a shared goal and are accountable to one another [46]. Although not all groups are teams, they are all considered groups. There are, however; certain prerequisites for working as a team. The aim, actions focus, procedures, resources, leadership, and members were all requirements. A lack of any of these requirements, according to Roosmalen [60], would reduce a potential team to a work group.

As a result, the term "team" was coined for organizations and academic fields since it was thought to be adaptable and sensitive to changing conditions, similar to how the term "cognitive" is used in academic areas and psychology and philosophy departments. Furthermore, in this evaluation, the ' team' was recommended to be utilized in place of a group for collective action, as cognitive was recommended to be used at the rural family level and at the RDAI School. In socioecological situations, people's cognitive abilities to cooperate in teams solve the collective action dilemma.

\section{References}

[1] Abafita Jaleta, Atkinson, J. and Kim, C. S. 2016. Smallholder commercialization in Ethiopia: Market orientation and participation. International food research journal, Vol, 23 (4): 1797-1807.

[2] Addisu Bezabeh. 2018. Collective action for technology transfer and commercialization: A systematic review of seed producer-farmer groups' seeds technology promotion and supply experiences in Ethiopia. Academic Research Journal of Agricultural Science and Research, Vol. 6 (9): 558-569.
[3] Agarwal, S. and Adjirackor, T. 2016. Impact of team work on organizational productivity in some selected basic schools in the Accra Metropolitan Assembly. European Journal of Business, Economics and Accountancy, UK, Vol. 4 (6): 40-52.

[4] Alem-meta Assefa A. and Singh, K. N. 2018. Factors affecting farmers' participation in watershed management programs in the north eastern highlands of Ethiopia: a case study in the Teleyayen sub-watershed: Department of Geography and Environmental Studies, Wollo University, Dessie, Ethiopia.

[5] Alem-meta Assefa A. and Singh, K. N. 2019. Factors affecting the adoption of sustainable land management practices at farm level in the north eastern highlands of Ethiopia: the teleyayen sub-watershed case study. Journal of Environ Pollution Manage Vol, 2 (103): 1-12.

[6] Ankur, S. K., Sondra, C. and Dnard, K. 2015. Likert Scale: Explored and Explained. British Journal of Applied Science and Technology, 1 (2): 11-27.

[7] Asfaw Zewdu and Fekadu Beyene. 2018. Factors affecting smallholder farmers' participation in degraded forest rehabilitation practices. The case of Gemachis district, Oromia region, Ethiopia. Journal of agricultural extension and rural development, Vol. 10 (11): 234-244.

[8] Berhanu Gebremedhin, Pender, J. and Girmay Tesfay. 2002. Collective action for grazing land management in croplivestock mixed systems in the highlands of northern Ethiopia: Background paper for the CAPRi Workshop on Methods for Studying Collective Action, February 25 March 1, 2002, in Nyeri, Kenya.

[9] Birhan Asmame M. and Assfa Abegaz Y. 2017. Determinants of farmers' adoption of land management practices in Gelana sub-watershed of Northern highlands of Ethiopia. Ecological processes (2017): 6-19.

[10] Bjorklund, D. F. 2013. Cognitive development: Anoverview. Oxford band book of development psychology, (1): 447-476.

[11] Choma, B. and McKeown, S. 2018. Intergroup contact and collective action: Integrative perspectives. Journal of Theoretical Social Psychology, 3 (9): 3-10.

[12] Daniel Jaleta N. 2020. Major constraints of watershed management practices in Ethiopia and ways forward. International journal of environmental protections and policy, vol, 8 (4): 70-76.

[13] David, G. 2014. Cognitive ability, character skills, and learning to play equilibrium: A Level-k Analysis. Discussion Paper No. 8236, Victoria Prowse Cornell University and IZA.

[14] Duncan, E. L. 2018. The psychology of collective action: The Oxford hand book of personality and social psychology. Oxford university press.

[15] Eswaran, H., Lal, R., Reich, P. 2001. Land degradation: response to degradation 1 (5): 20-35.

[16] Etenesh Bekele. 2018. Farmers collective action and agricultural transformation in Ethiopia: Degree of $\mathrm{PhD}$. in developmental studies at the University of South Africa.

[17] Faysse, N. and Ben Mustapha, A. 2017. Finding common ground between theories of collective action: The potential of analyses at a Meso-Scale. International journal of the commons, Vol. 11 (2): 928-949. 
[18] FDRE (Federal Democratic Republic of Ethiopia). 1994. Constitution of the Federal Democratic Republic of Ethiopia, 1994 Ethiopia.

[19] Fekadu Beyene. 2009. Collective action in water-point management: The case of pastoral and agro-pastoral communities in eastern Ethiopia. Journal compilation United Nations: Natural Resources Forum, 33 (2): 175-188.

[20] Fekadu Beyene. 2010. Interclan cooperation in a risky pastoral ecology: Some lessons from Eastern Ethiopia. Springer Science + Business Media. Hum Ecol, 38 (3): 555-565.

[21] Francesco, G. 2012. Reciprocity: Weak or strong? What punishment experiments do (and do not) demonstrate: Department of economics, University of Milan, 20122, Italy.

[22] Freeman, J., Baggio, A. J. and Coyle, R. T. 2020. Social and general intelligence improves collective action in a common pool resource system. Sustainability science, PNAS, Vol, 117 (14): 7712-7718.

[23] Friedenberg, J. and Silverman, G. 2006. Cognitive Science: An Introduction to the study of mind. Sage publications, Inc.order@sagepub.com. Accessed 19 April 2020.

[24] Gebrehaweria Gebregziabher, Dereje Assefa A., Girmay Gebresamuel, Giordano, M. and Langan, S. 2016. An Assessment of Integrated Watershed Management in Ethiopia. Colombo, Sri Lanka: IWMI. doi: 10.5337/2016.214. Accessed 10 December 2020.

[25] Gebremedn Tesfaye, Tena Alamirew, Asfaw Kebede and Gete Zeleke. 2018. Institutional functionality in participatory integrated watershed development of Tana Sub-Basin, Ethiopia: Land (5): 1-17.

[26] Getachew Shambel E., Kibwika, P., Jemal Yousuf, H. and Bernard B. O. 2017. Harnessing social capital for resilience to livelihood shocks: Ethnographic Evidence of indigenous mutual support practices among rural households in Eastern Ethiopia. International Journal of Population Research Volume, 1 (3): 1-26.

[27] Gudeta Kebede A. 2019. Citizens' trust in public and political institutions in Ethiopia: College of Law and Governance, Jimma University, Ethiopia.

[28] Gutman, M. 2014. Campaign hand book: Auser's guide to campaigning. Green European Foundation, Brussels Office, Belgium.

[29] Hancock, B. 1998. Trent focus for research and development in primary healthcare: An introduction to qualitative research. Trent Focus.

[30] Holzinger, VanK. 2003. The problems of collective action: A new approach, Preprint sausder Max-Planck-Projekt gruppe Rechtder Gemeinschaftsguter, Bonn.

[31] Hoque, E. Md. 2017. Three domains of learning: Cognitive, affective and psychomotor. The Journal of EFL Education and Research (JEFLER) Vol. 2, (6): 45-52.

[32] Ingram, J., Chiswell, H., Mills, J., Debruyne, L., Cooreman, H., Koutsouris, A., Pappa, E. and March and, F. 2018. Enabling learning in demonstration farms: A literature review. $13^{\text {th }}$ European International Farming Systems Association (IFSA) Symposium, Greece: International. J. Agricultural Extension, (10): 29-42.
[33] Johann, F. K., Andrew, R. D., Colin, P. and Nick V. 2009. Institutional economics view son African agricultural development: Food policy research institute W.D.C.U.S.A.

[34] Kerr, J., Milne, G., Chhotray, V., Baumann, P., James, A. 2007. Managing watershed externalities in India: Theory and practice. Environment, Development and Sustainability, 9 (7): 263-281.

[35] KidaneTafa. 2018. Participation in watershed management programs and adoption of sustainable land management practices in Bassonaworana District, Central Highlands of Ethiopia: PhD Dissertation, Adis Ababa University, Ethiopia.

[36] Kim, K. Y., Edens, D., Iorio, M. f., Curtis, C. J., Romero, E., 2015. Cognitive skills development among international students at research universities in the United States. Journal of International Students, Vol, 5 (4): 526-540.

[37] Kitapc, I. 2016. The changing structure of the concept of capital: Cognitive social capital. Pamukkale university faculty of economics and administrative Sciences department of public finance, Uluslararası Ekonomik Araştırmalar Dergisi, Eylül, 2 (3): 13-23.

[38] Lakew Desta, Carucci, V., Asrat Wendem-Ageňehu and Yitayew Abebe. 2005. Community based participatory watershed development: A guideline, Ministry of Agriculture and Rural Development, Addis Ababa, Ethiopia.

[39] Liang, Q., Huang, Z., Luc, H. and Wangd, X. 2015. Social capital, member participation, and cooperative performance: Evidence from China's Zhejiang. International Food and Agribusiness Management Review Volume, 18 (5): 49-78.

[40] Lulseged Tamene, Kindu Mekonnen, Kifle Woldearegay and Berra Adie. 2014. Report of an integrated watershed management and water harvesting training workshop and experience sharing visit in the Ethiopian highlands. Published by ILRI.

[41] McElreath, R., Timothy. R., Clutton-Brock, H., Fehr, E., Daniel, M. T., Edward, F., Hagen, H., Hammerstein, P., Kosfeld, M., Silk, J. and Wilson, M. I. 2003. Group report: The role of cognition and emotion in cooperation. Genetic and Cultural Evolution of Cooperation, (7): 125-152.

[42] Meinzen-Dick, R., Gregorio, M. D. and McCarthy, N. 2004. Methods for studying collective action in rural development: International Food Policy Research Institute 2033 K. Street, N. W. Washington, D.C. 20006, U.S.A.

[43] Mekonen Debara, Yisak Gecho, and Teklu Gebretsadik. 2016. The role of community based watershed management for climate change adaptation in Kindo Koyisha Woreda of Wolaita Zone. Journal of Food, Environmental Science, V, 3 (11): 70-86.

[44] Million Sileshi, Kadigi, R., Mutabazi, K. and Sieber, S. 2019. Determinants for adoption of physical soil and water conservation measures by smallholder farmers in Ethiopia: doi.org/10.1016/j.iswcr.2019.08.002. Accessed 10 March 2020.

[45] Muluken Gezahegn, W. and Maria Sassi. 2017. Impact of farmers' training centres on household income: Evidence from propensity score matching in Eastern Ethiopia. Journal of Social Sciences (2017): 1-12.

[46] Mwhite, D. 2002. ROADMAP, Groups and Teamwork: "Team-building events are more likely to succeed if they include outsiders and unexpected activities,"http://www.News.ft.com. Accessed 1 May 2020. 
[47] Nagle, G. 2006. Geo fact sheet: Soil degradation-A creeping concern. Journal of Curriculum press, bank house, 105 king street, Wellington, ISSN (2006): 1351-5136.

[48] Njuki, J., Mapila, M. T., Zingore, S. and Delve, R. 2008. The dynamics of social capital in influencing use of soil management options in the Chinyanja Triangle of southern Africa. Ecology and Society, 13 (2): 9-19.

[49] North, D. C. and Thomas, R. P. 1973. The rise of the western world: A new economic history. NewYork: Cambridge University press, 1973

[50] Olson, M. 1965. The logic of collective action: Public goods and the theory of groups. Cambridge, MA: Harvard University Press.

[51] Ostrom, E., Gardner, R., Walker, J. 1994. Rules, games and common-pool resources: The University of Michigan Press, Ann Arbor.

[52] Ostrom, E. 1999. Social capital: A fedora fundamental concept? In Social capital: A multi faceted perspective. Ed. P. Washington DC, USA: World Bank.

[53] Ostrom, E. 2005. Doing institutional analysis: Digging deeper than markets and hierarchies. (Eds.), Hand book of New Institutional Economics. Springer.

[54] Ostrom, E. 2011. Background on the institutional analysis and development framework. Policy Studies Journal, 39 (1): 1-27.

[55] Pugel, K., Javernick-Will, A., Walters, J. and Linden, K. 2018. Factor and Actor Networks: Alignment of collective action groups for water sustainability in Ethiopia: Bryan Franz, University of Florida and Iva Kovacic, TU Wien.

[56] Putnam, R. D. 1993. The prosperous community: Social capital and public life. American Prospect, 13 (3): 35-42.

[57] Ramalingam, M., Kasilingam, G. and Chinnavan, E. 2014. Assessment of learning domains to improve student's learning in higher education: Faculty of engineering and computer technology, school of physiotherapy, AIMST University, K, Malaysia.

[58] Robert, J., Jones, A. and Montanarella, L. 2002. Land degradation: Contributions to the international workshop, European commission, Ispra, Italy.

[59] Roger, D. 2015. The logic of collective action and beyond: Professor of economics West Virginia University.

[60] Roosmalen, T. M. 2012. Questionnaire on teamwork and team Effectiveness. The Norwegian University of Science and Technology.

[61] Samuel Assefa, Kessler, A. and Fleskens, L. 2019. Assessing farmers' willingness to participate in campaign-based watershed management: Experiences from Boset District, Ethiopia: The Netherlands.

[62] Samuel Assefa H. 2020. Participatory agent-based modeling for sustainable watershed management in the central rift valley of Ethiopia. PhD thesis, Wageningen University, the Netherlands.

[63] Sandler, T. 2015. Collective action: Department of economics, school of economic, political \& policy sciences, University of Texasat Dallas, 800 W. Camp bell Rd., Richardson, TX75080, USA, openaccessatSpringerlink.com, 164 (2015): 195-216.
[64] Seline, S. M., Delia, C. 2015. The role of knowledge, attitudes and perceptions in the uptake of agricultural and agro forestry innovations among smallholder farmers in SSA. International journal of agricultural sustainability, 13 (1): 40-54.

[65] Sonmez, V. 2017. Association of cognitive, affective, psychomotor and intuitive domains in education, Sönmez Model: Faculty of education, Cyprus International University, Cyprus. Universal Journal of Educational Research, 5 (3): 347-356.

[66] Suhas, P. W. and Kaushal, K. G. n. d. Watershed management concept and principles: International crops research institute, Patancheru, Andhra Pradesh, India.

[67] Sverker, C. J., Niklas, H., Åsa, L., Martin, S., Francisco, A., Bengt, B., David, L., Andreas, N., Bethanie, C. A., Sam, D. and Will, S. 2019. On the preconditions for large-scale collective action: The centre for University of Gothenburg, Sweden.

[68] Taiwo, T. M. 2019. An introduction to logic and critical thinking: International Journal of Research and Innovation in Social Science (IJRISS) Ekiti State University, Nigeria, Vol, 3 (2): 28-34.

[69] Tesfaye Lemma, T. 2009. Supply response, local reality and livelihood sustainability: the policy dilemma of khat (Cathae dulis) production in eastern Ethiopia: International Journal of Agricultural Sustainability, 7 (3): 176-188.

[70] Tesfaye Yaekob, Lulseged Tamene, Solomon G. Gebrehiwot, Solomon, S. Demissie, Zenebe Adimassu, Kifle Woldearegay, Kindu Mekonnen, Tilahun Amede, Wuletawu Abera, John W. R., Dawit Solomon and Thorne, P. 2020. Assessing the impacts of different land uses and SWC interventions on run off and sediment yield at different scales in the central highlands of Ethiopia: Cambridge University.

[71] Thorat, M. M. 2017. Watershed management: International research. Journal of Science and Engineering, 5 (7): 81-83.

[72] Tozier, P. A., Burch field, E. K. and Carrico, A. R. 2018. The implications of group norms for adaptation in collectively managed agricultural systems: evidence from Sri Lankan paddy farmers. Ecology and Society, 23 (3): 21-39.

[73] UNCCD (United Nations Convention to Combat Desertification). 2014. Land degradation neutrality: Resilience at local, national and regional levels, Bonn, Germany.

[74] Wang, Y. 2010. Industry expansion, organization innovation, and farmer cooperative growth. China Rural Survey (2): 47-50.

[75] Wani, S., Sreedevi, T., Reddy, T. V., Ven kateswarlu, B. and Prasad, C. 2008. Community watersheds for improved livelihoods through consortium approach in drought prone rain-fed areas. Journal of Hydrological Research and Dev., 23 (6): 55-77.

[76] WB (World Bank). 2012. Agricultural innovation systems: an investment source book. Washington, D. C. USA. www.worldbank.org. Accessed on 11 November 2020.

[77] WB (World Bank). 2013. Ethiopia's Productive Safety Net Program (PSNP) integrating disaster and climate risk management: Case study. Washington, DC. USA.

[78] WB (World Bank). 2019. For a climate action through landscape management program for results: Environment and Natural Resources Global Practice Africa Region. 
[79] Weimann, J., Brosig-Koch, J., Heinrich, T., Hennig-Schmidt, H. and Keser, C. 2018. The logic of collective action revisited. Working paper of CIRANO Allier savoir et decision. weimann@ww.uni-magdeburg.de. Accessed 7 December 2020 .

[80] Wilson, D. S., John, J. T. and Ralph, R. M. 2014. Cognitive cooperation: When the going gets tough, thank as a group. Human nature, Vol, 15 (3): 1-15.

[81] Wuletaw Mekuria. 2019. Integrated watershed management practices: Evidences from Tsegur and Kanat MicroWatersheds of the Ethiopian highlands. Journal of Agric Forest Meteorol Res, 2 (3): 123-125. 